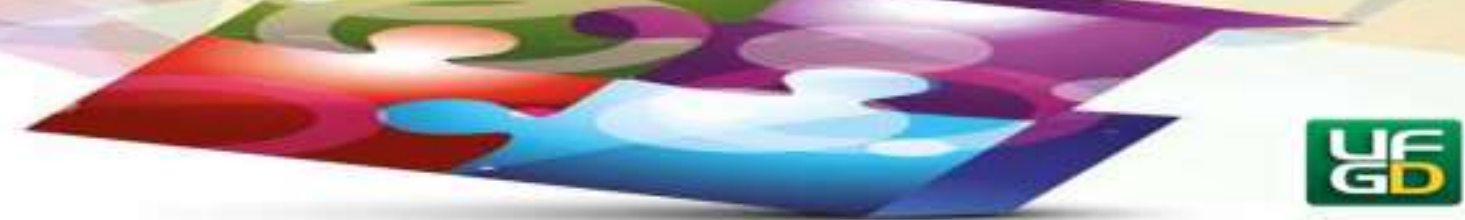

\title{
PARTICIPAÇÃO E GESTÃO DEMOCRÁTICA DA EDUCAÇÃO: O LEGISLADO É O PRATICADO?
}

\section{DEMOCRATIC PARTICIPATION AND MANAGEMENT OF EDUCATION: IS

\author{
LEGISLATE PRACTICED?
}

\author{
Nilson Francisco da SILVA ${ }^{1}$ \\ Maria Alice de Miranda ARANDA ${ }^{2}$
}

\begin{abstract}
Resumo: O presente estudo tem por objetivo discutir a concepção de participação como princípio da gestão democrática na legislação educacional do nacional ao local. Pautado na metodologia de caráter qualitativa, delineada pela pesquisa bibliográfica e documental. Como aportes bibliográficos faz uso da literatura que traz a gestão democrática da educação e a participação como objetos de análise e como aportes documentais, faz destaque para imperativos legais que normatizam os temas em relevo. Na pesquisa maior com a finalidade de materializar uma Dissertação de Mestrado, a empiria tem o PME como objeto de investigação e os lócus, o Município de Dourados, MS. A problemática que aqui se coloca é em relação ao que é legislado e ao que de fato é praticado e traz para o debate a prevalência de concepções várias que permeiam projetos em disputa e a meritocracia. Em resumo, gestão democrática e participação, se concebidas apenas pela legislação, pelo "cumpra-se", podem vir a ser "letra morta".
\end{abstract}

Palavras-chaves: Gestão democrática da educação. Participação. Legislação educacional.

Abstract: This study aims to discuss the conception of participation as a principle of democratic management in educational legislation from national to local. Guided by the qualitative methodology, delineated by bibliographical and documentary research. As bibliographical contributions makes use of the literature that brings the democratic management of education and participation as objects of analysis and as documentary contributions, emphasizes legal imperatives that normalize the topics in relief. In the larger research with the purpose of materializing a Masters Dissertation, the empiria has the SME as object of investigation and the locus, the Municipality of Dourados, MS. The problem that arises here is in relation to what is legislated and what is actually practiced and brings to the debate the prevalence of various conceptions that permeate disputed projects. In short, democratic management and participation, if conceived only by legislation, by "complying", can become "dead letter."

Keywords: Democratic management of education. Participation. Educational legislation.

\section{Introdução}

\footnotetext{
${ }^{1}$ Mestre em educação pela Universidade Federal da Grande Dourados (UFGD). E-mail: nil0911@yahoo.com.br

${ }^{2}$ Professora Doutora na Faculdade de Educação da UFGD. E-mail: mariaaranda@ufgd.edu.br
} 


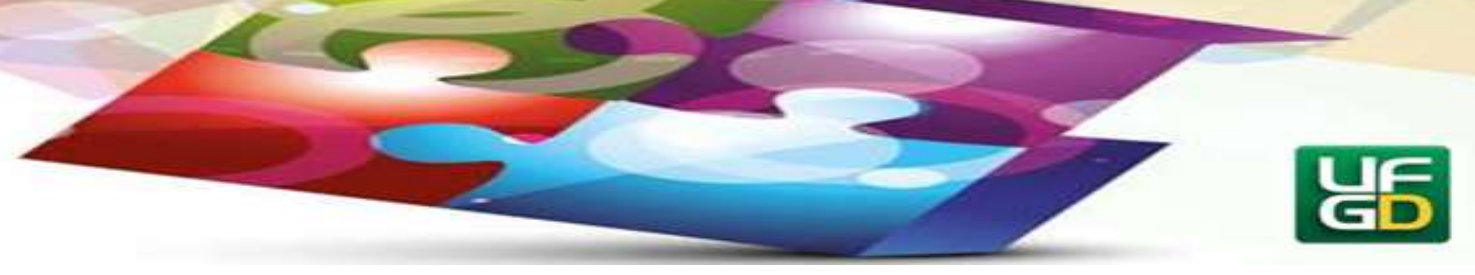

O presente estudo tem por objetivo discutir a concepção de participação como princípio da gestão democrática na legislação educacional do nacional ao local. Está pautado em uma metodologia de caráter qualitativa, delineada pela pesquisa bibliográfica e documental. Como aportes bibliográficos faz uso da literatura que traz a gestão democrática da educação e a participação como objetos de análise e como aportes documentais, faz destaque para imperativos legais que normatizam os temas em relevo. Como nacional, destaca a Constituição Federal/1988 (CF/1988), a Lei de Diretrizes e Bases da Educação Nacional (LDB/1996) e o atual Plano Nacional de Educação (PNE/2014-2024). E como local, o Plano Municipal de Educação de Dourados (PME/Dourados-MS, 2015). A problemática que se aqui se coloca é em relação ao que é legislado e o que de fato é praticado, trazendo para o debate a prevalência de concepções várias que permeiam projetos em disputa, no macro, a sociedade capitalista, e, no micro, o espaço educacional local.

A legislação educacional brasileira, com foco na educação pública, é elucidativa no que tange a gestão democrática e um dos princípios necessários à sua materialização, no caso, a participação (ARANDA, 2014). No artigo 206 da CF/1988 está assim definido: “O Ensino será ministrado com base nos seguintes princípios: [...] VI - Gestão democrática do Ensino público, na forma da lei [...]" (BRASIL, 1988).

A Carta Magna de 1988 define a forma de gestão, porém evidencia que os entes federativos elaborem as diretrizes legais para a efetivação de gestão democrática da educação. Por meio do princípio constitucional maior, um importante passo foi dado em prol da efetivação da gestão democrática da educação.

$\mathrm{Na}$ LDB/1996, está o imperativo para os sistemas de ensino normatizar e estabelecer as diretrizes para a efetivação da gestão democrática da educação. No Artigo 14 está registrado o atendimento legal "as normas da gestão democrática na Educação Básica de acordo com suas peculiaridades [...]" e estabelece que os sistemas de ensino devam buscar e fazer a gestão democrática, mediante os seguintes princípios: "I - participação dos profissionais da educação na elaboração do projeto pedagógico da escola; II - participação das comunidades escolar e local em conselhos escolares ou equivalentes" (BRASIL, 1996, grifos nossos). 


\section{HORIZONTES - REVISTA DE EDUCACATO}

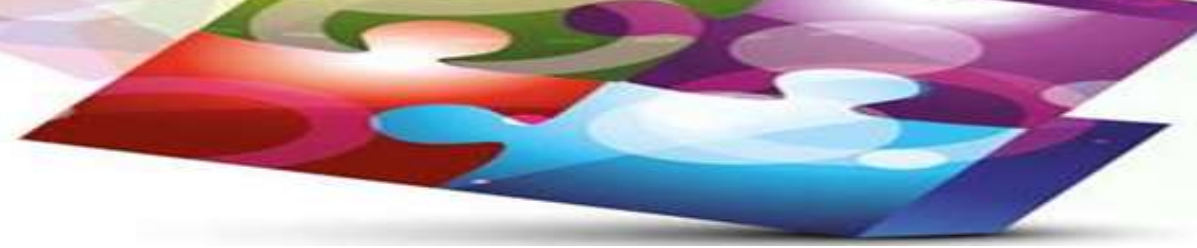

Ou seja, democratização ensejada pela CF/1988 foi seguida, na forma da lei, pela LDB/1996, que no Título II trata dos princípios e fins da educação nacional e no Artigo $3^{\circ}$, Inciso VIII, reafirma que "gestão democrática do ensino público, na forma desta Lei e da legislação dos sistemas de ensino" (BRASIL, 1996).

O Plano Nacional de Educação, Lei 13.005 de 2014 (PNE/2014-2024), segue a mesma linha da CF/1988 e da LDB de 1996 em relação à gestão democrática da educação, referendada em dois momentos, no primeiro no Artigo $2^{\circ}$ que trata das diretrizes: “[...] VI - promoção do princípio da gestão democrática da educação pública [...]” (BRASIL, 2014), além de outras seis diretrizes que referenda o Artigo 206 da CF/1988.

Cury (2002, p. 166) observa que "a ordem constitucional que nasceu em 1988 consagrou princípios caros à democracia e à educação democrática”.

A Meta 19 do PNE/2014-2024 tem o que segue: "assegurar condições, no prazo de dois anos, para a efetivação da gestão democrática da educação" [...] (BRASIL, 2014). Meta que vêm disciplinar os Estados, os Municípios e o Distrito Federal para que elaborem leis próprias com vistas a assegurar a efetivação da gestão democrática da educação.

O imperativo do PNE/2014-2024, é seguido, com todas as letras, pelo PME/Dourados, MS, inclusive, com os critérios que servirão de base para a efetivação da gestão democrática no espaço escolar: [...] associada a critérios técnicos de mérito e desempenho e à consulta pública à comunidade escolar, no âmbito das escolas públicas prevendo recursos e apoio técnico da União para tanto (DOURADOS, 2015, grifos nossos).

São critérios que pressupõem a democracia, mas cabe discutir: que critérios são esses? O que eles querem dizer? Qual democracia? Sob qual concepção de participação? São questões que os sujeitos educacionais, comprometidos com uma educação de qualidade social, a qualidade que prima pelo ser humano em detrimento à qualidade total, esta última concebe o ser humano como mercadoria e a qualidade social referência outra sociedade (ARANDA e LIMA F., 2014) justa e igualitária, buscam respostas.

Nessa direção a Meta 19 aponta que o critério técnico para a verificação da gestão democrática, perpassa pelo mérito, consulta pública e financiamento para a execução com recursos da União. Sinaliza-se, portanto, avaliações que se baseiam na meritocracia. 


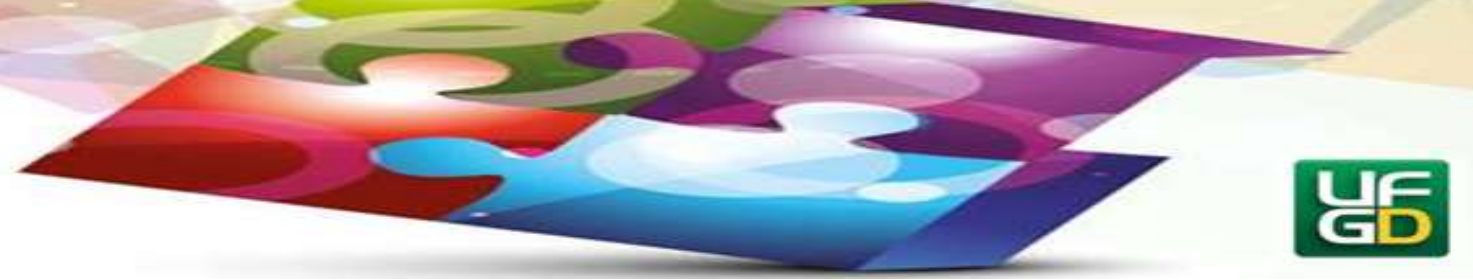

No dicionário online Aurélio de Língua Portuguesa, a meritocracia e definida como "1 - forma de liderança que se baseia no mérito, nas capacidades e nas realizações alcançadas, em detrimento da posição social” (FERREIRA, 2018).

Penna e Bello (2015, p. 16) entende e descreve a meritocracia “[...] como uma categoria de um modelo de gestão que valoriza indivíduos com base no mérito, considerando o seu desempenho e a sua produção, de acordo com parâmetros ditados pelo mercado capitalista", ou seja, quem dita às regras é o mercado e este não considera as particularidades individuais de cada sujeito.

Dessa maneira, esse modelo considera que todos tiveram "as mesmas oportunidades" e se acaso o fracasso acontecer é por que o individuou não se esforçou e não aproveitou as oportunidades.

A visão meritocrática, além de complexa é injusta desconsidera a diversidade social vivenciada no Brasil com tamanha disparidade na distribuição de renda não garantindo igualdade e equidade aos bens e serviços a todo sujeito, “[...] o ideal meritocrático consiste em dar a mesma coisa a todos, e sabemos que, no caso da escola, estamos longe disso" (DUBET, 2004, p. 545). É preciso ficar atento, pois a “[...] igualdade de oportunidades meritocrática supõe igualdade de acesso" (DUBET, 2004, p. 541) e tal conceito para uma vertente crítica e dialética é totalmente errônea.

Nessa direção a Meta 19, se apresenta de modo geral engessada e a mercê da cultura da meritocracia. Apresenta critérios que não favorece na formação de sujeitos críticos e autônomos, mais procurar valorizar a cultura da eficaz e eficiência. E essa cultura é do mercado "que se guia, nas atuais circunstâncias, pelos mecanismos das chamadas 'pedagogia das competências' e 'qualidade total"” (Saviani, 2007, p. 1253).

\section{Princípio básico para efetivação da democracia: a participação}

Antes de abordarmos o tema gestão democrática da educação, faz-se necessário referirmos do princípio básico para a efetivação da mesma que é participação. Autores como Penna e Bello (2015, p. 91) afirmam que: “compreende-se a participação como elemento importante numa gestão que pretenda ser democrática até mesmo como forma de aprendizado para todos os envolvidos". 


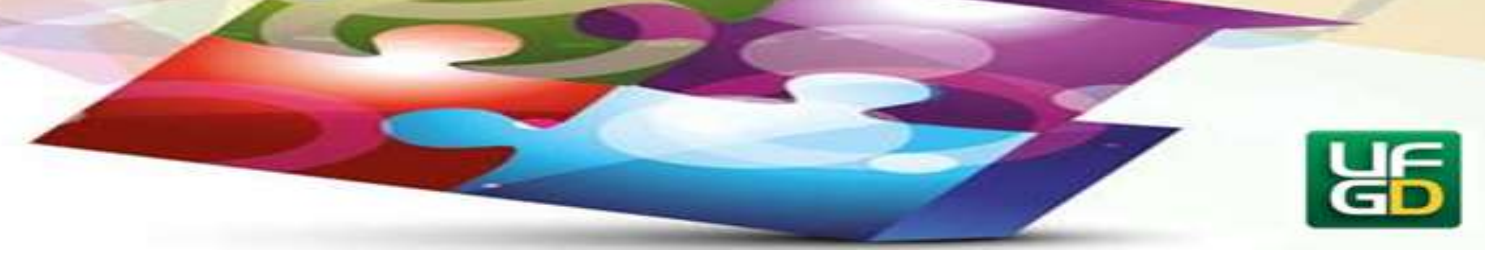

Percebe-se, portanto, que para efetivação da gestão democrática da educação e necessário a participação de topos os envolvidos. Não há democracia sem participação. Aranda (2014) entende que a participação é:

[...] um princípio democrático primordial, um preceito legal, uma categoria histórica que se constrói nas relações sociais e, em específico, na área educacional é um tema presente na intrincada relação entre a gestão da educação, o Estado e a sociedade, categorias que alicerçam a política educacional brasileira (ARANDA, 2014, p. 266).

O conceito de participação ${ }^{3}$ na gestão democrática, nas palavras de Alves (2010, p. 11), é "efetiva, direta e indireta da sociedade em todos os níveis de decisão e execução da educação, com real poder de interferência e manifestação dos anseios comunitários".

Logo, evidencia-se que um dos desafios para a efetivação da gestão democrática é a manutenção da participação de todos os envolvidos nos processos de decisão coletiva, no interior das escolas.

Perceba, portanto, que a participação é um princípio democrático ${ }^{4}$ eficiente que dá suporte a gestão democrática, ao Estado e a sociedade. Ou seja, sem participação não existe democracia a fim de garantir que todos se façam ouvir-se nos processos de decisões coletiva.

Nessa direção, a gestão democrática pressupõe a descentralização de poder, participação e socialização. Segundo Hume (1999, p. 10) “O homem é um ser sociável do mesmo modo que racional" e a escola é o espaço onde as manifestações sociais e racionais ocorrem ou pelo menos se almeja que ocorra. É preciso, no entanto, que se pratique no dia-a-dia escolar um exercício de democracia, vez que a gestão em foco a ela remete.

Desde a antiguidade, há um debate em torno da questão democracia, até porque não é “[...] uma questão simples, considerando que para chegar a compreensão de seu significado, conceito ou concepção é preciso contextualizá-la num período histórico” (ARANDA, 2014, p. $95)$.

\footnotetext{
${ }^{3}$ Para Alves (2010, p. 15): A participação na gestão democrática é Participação efetiva, direta e indireta da sociedade em todos os níveis de decisão e execução da educação. Na gestão gerencial a participação da comunidade escolar, se dá como controladores e fiscalizadores das políticas públicas e como executores das tarefas previamente pensadas e planejadas e na compartilhada é pontual, filantrópica.

${ }^{4}$ Democracia é entendida como uma das formas de governo do povo, pelo povo e para o povo (ARANDA, 2009, p. 21-22)
} 


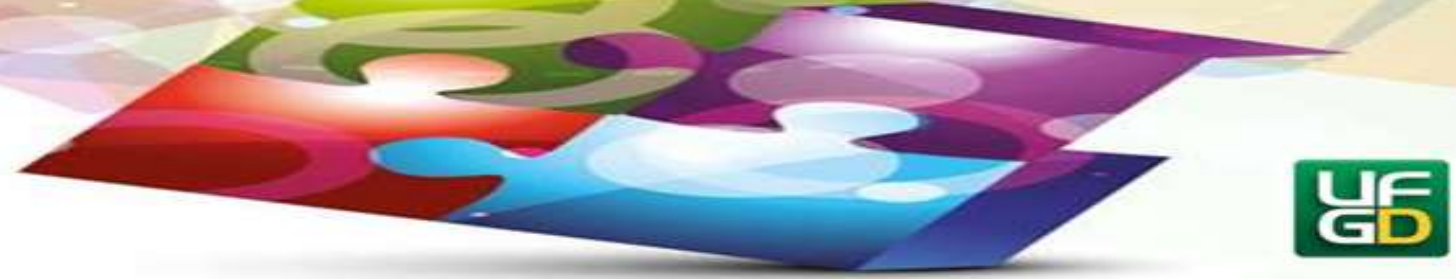

Nesse contexto a participação, é um tema bastante debatido por estudiosos progressistas a fim de incentivar profissionais da educação, trabalhadores, pais e alunos a se apropriem desse direto conquistado sob pena de muitas lutas.

Como referendado por Aranda, (2014, p. 277) "[...] é sempre bom frisar que a participação está entre projetos de sociedade em disputas, daí advém várias possibilidades e variadas práticas, desde um modelo ficcional/ilusória, [...] até modelos mais complexos que visam a transformação política e social.

Não há, portanto, transformação social e política sem a ativa participação das classes trabalhadoras, ou melhor, se essa classe não tiver consciência que não existe outro modo de se conseguir a transformação social, sem o enfrentamento contra as estruturas hegemônicas de poder, estará sempre fadada em não participar dos processos decisórios ficando assim sem condições de embates na arena de disputas na sociedade de classes.

Logo, para que os sujeitos tenham tal consciência é preciso desenvolver a "cidadania ampliada", utilizar- se de todos os instrumentos legais que pressupõe a participação e autonomia.

Carnoy (1988, p. 177), explica que “o desenvolvimento da consciência da classe trabalhadora, elemento crucial na teoria marxista, é para Gramsci o momento principal para explicar tanto o domínio do capitalismo quanto a sua derrocada”.

De fato, não há outro caminho a não ser o despertar da consciência para "evidenciar um capitalismo com rosto humano" (ARANDA, 2015, p. 42).

Contudo a consciência da classe trabalhadora é o primeiro passo para a participação das massas em movimentos coletivos de decisão, é ter na prática o poder nas mãos. Ou seja, ter responsabilidade e autonomia ao mesmo tempo e praticar a cidadania ampliada. Aranda, (2015) reforça:

Esse entendimento de cidadania remete a um modo/forma de participação consubstanciada pelos direitos individuais, civis, políticos e sociais, todos reconhecidos pelo Estado, sendo esses direitos, no caso brasileiro nos dias

\footnotetext{
${ }^{5}$ Aranda (2015, p. 50) a "cidadania ampliada" não é colocada como alternativa ao padrão de civilização vigente nesse momento do capitalismo, mas como uma alternativa para que todos possam ser contemplados em suas necessidades básicas com possibilidades de condições mais dignas de vida, em todos os aspectos, em especial no tocante a uma educação de qualidade que capacite o cidadão a enfrentar as complexidades da sociedade onde está inserido.
} 


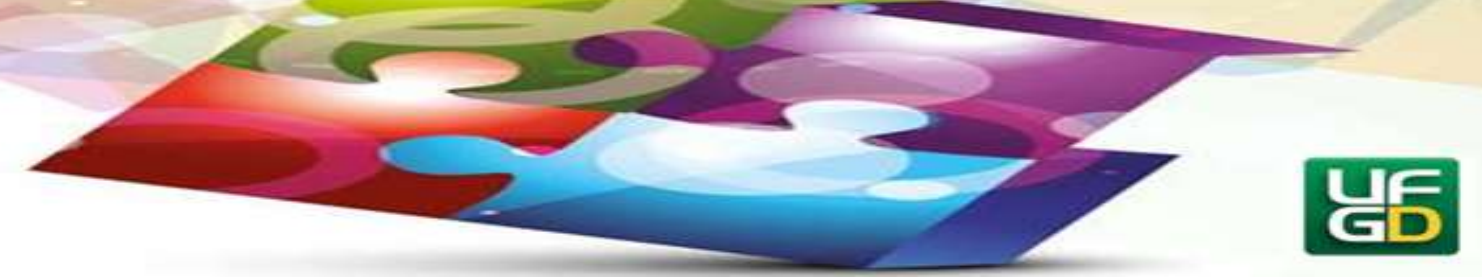

atuais, imperativos legais assegurados na Constituição Federal em vigor (ARANDA, 2015, p. 50).

Neste contexto, quando o coletivo começa a ter consciência da importância da participação estes começam a praticar a cidadania ampliada. Os sujeitos participam com qualidade e são importantes no processo de decisões.

Deixam, portanto, de serem meros figurantes, quando participam de processos para apenas referendar aquilo que já foi decidido. E acima de tudo passam a também a exigir por parte do Estado, por exemplo, a formulação e implementação de Políticas Educacionais eficazes que contribuam significativamente com a qualidade social do ensino público.

Portanto, é preciso romper com as práticas antidemocráticas enraizadas do período militar (1964-1985). Marcados por [...] "momento de conflitos, de lutas travadas pela defesa de projetos alternativos de sociedade e de educação em oposição a então política hegemônica representada pelos militares [...]" Aranda (2009, p. 21). Embates realizados a fim de promover projetos alternativos e democráticos.

Percebe-se que muito foi feito pela sociedade civil, educadores e movimentos sociais para a democratização do país. Porém em tempos de retrocessos, ${ }^{6}$ vivenciados atualmente, é preciso resistir. Daí a importância da conservação e incentivo a participação para a efetiva manutenção de espaços democráticos de decisões coletivas.

Nesse contexto é "preciso aprofundar a reflexão, pois a questão envolve maior grau de complexidade do que aparenta" (SPÓSITO, 2005, p. 45). Portanto, na gestão democrática e a participação efetiva dos segmentos envolvidos no processo da educacional é um imperativo decisivo para implementação de uma sociedade democrática por meio da gestão:

Nesse sentido, a democratização da gestão escolar implica a superação dos processos centralizados de decisão e a gestão colegiada, na qual as decisões nasçam das discussões coletivas, envolvendo todos os segmentos da escola, e orientadas pelo sentido político e pedagógico presente nessas práticas (BRASIL, 2015).

\footnotetext{
${ }^{6}$ Ver a Emenda Constitucional $n^{\circ} 95$, de 15 de dezembro de 2016 que estabelece o novo regime fiscal no Brasil por 20 anos.
} 


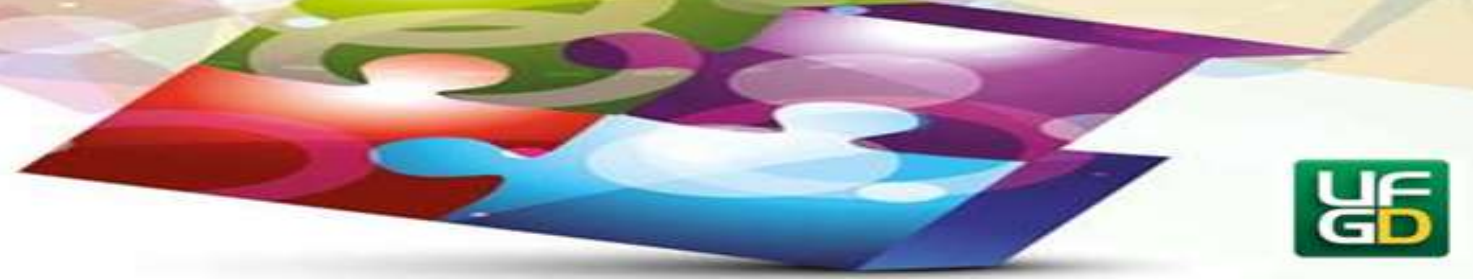

Nessa direção, só se efetiva a gestão democrática com a verdadeira participação dos envolvidos. Logo, não existe meio termo, a classe trabalhadora, precisa participar e essa participação tem que ser de qualidade. Para estar firmes na luta, desenvolver a consciência ampliada, a autonomia e lutar por aperfeiçoamentos de espaços democráticos de decisão.

Pois, a participação sempre será um mecanismo eficaz na efetivação e garantia da democracia da educação e a efetivação dos sujeitos como autores da sua própria história. Lima; Aranda; Lima, (2013) reforçam que:

\begin{abstract}
Entende-se a participação como uma categoria histórica construída nas relações sociais, um princípio orientador de ações que precisam ser constantemente aprendidas e apreendidas de modo que o homem possa se constituir em sujeito da história, possa fazer a história, mesmo com a percepção de que nessa estrutura social as condições para esse fazer não lhe são dadas a priori, mas precisam ser conquistadas no movimento histórico presente nas relações sociais, políticas e econômicas [...] (LIMA; ARANDA, LIMA, 2013 p. 57).
\end{abstract}

Nenhum sujeito nasce participativo, crítico e social, precisa ser aprendido, ensinado e acima de tudo praticado. $\mathrm{O}$ ato de participar precisa ser constantemente praticado até porque a sociedade que vivemos é cercada de interesses e disputas pelo poder. Os embates entre as sociedades de classes existem e os sujeitos da classe trabalhadora precisam ter consciência, autonomia e fazer valer seu direito de participação a fim de promover a verdadeira cidadania.

\title{
Gestão democrática da educação e participação
}

Há uma vasta legislação brasileira no que tange a Gestão democrática. Iniciando pela Constituição Federal de 1988 (CF/1988) a Lei de Diretrizes e Bases da Educação (LDB/9.394), o Plano Nacional de Educação (PNE/2014-2024), o Plano Estadual de Educação do Estado de Mato Grosso do Sul (PEE-MS) e o Plano e o Plano Municipal de Educação de Dourados (PME/ Dourados-MS, 2015) dentre outros documentos importantes que tem como objetivo promover a participação e democracia como princípio da gestão democrática.

Para Bobbio, (1997, p. 18) a democracia é "entendida como contraposta a todas as formas de governo autocrático, é o de considerá-la caracterizada por um conjunto de regras 
(primárias ou fundamentais) que estabelecem quem está autorizado a tomar as decisões coletivas e com quais procedimentos".

Temos a consciência que a manutenção da democracia não é um fator simples, devido a lutas de classes, disputas pelo poder e os interesses ideológicos que perpassam na sociedade, pois a "democracia é construção coletiva, em que embates são travados e perdas e ganhos acontecem” (Raimann, 2015, p. 58).

Não há democracia sem embates, sem discordância, ou seja, todos precisam ser ouvidos a fim que a vontade da maioria seja estabelecida. Sendo a democracia um sistema mais justo que já vivenciamos no Brasil precisa ser modernizada, completa e, sobretudo que atenda os interesses da classe trabalhadora.

Aranda, (2014, p. 269), entende a democracia como “[...] restrita, mínima, camuflada, maquiada, tutelada”. Oliveira, (2005) completa que:

[...] a democracia que se desenvolve no Brasil seria uma democracia a meio caminho, que não se efetiva, não se consubstancia, podendo ser duradoura ou mesmo permanente, mas mantendo-se meramente formal e conservando os grupos privilegiados de sempre (OLIVEIRA, 2005, p. 14).

É notório e é percebido por estudiosos que nossa recente democracia não é consolidada. Atende interesses de grupos ideológicos e do capital financeiro. Sendo assim embora tenhamos uma vasta legislação que tem por objetivo a efetivação da participação como princípio de gestão democrática da educação. Esta participação não é plena, não tem qualidade não é crítica.

A participação plena é um princípio básico para efetivação da gestão democrática. Pois “democracia é participação e corresponsabilidade. Participação não é participacionismo, requer engajamento e poder compartilhado, que se pulveriza no coletivo" (Raimann, 2015, p. 59).

Porém esta participação plena com corresponsabilidade se efetiva na prática nos dias atuas? De qual maneira? A vasta legislação atual tem conseguido fomentar a participação crítica, emancipatória, igualitária, corresponsável?

Lima; Aranda; Lima (2013) afirmam que:

[...] a democracia não tem conseguido se articular a uma concepção que legitime seus valores efetivos, e empiricamente é afirmado que a participação é reduzida, restrita, mínima, controlada, regulada, cooptada, suscitando-se 


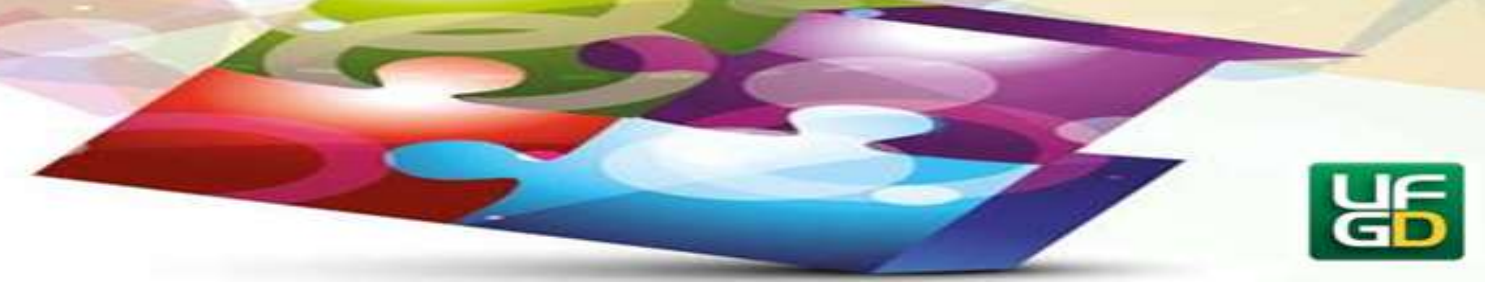

posicionamentos vários, dentre eles aqueles que apregoam que a participação da população não tem sentido, [...] (LIMA; ARANDA; LIMA, 2013, p. 57).

Os autores advertem que a democracia não conseguiu produzir de fato mecanismos suficientes para a efetivação da verdadeira participação, para eles ela [participação] não é legitima, não é plena, não é verdadeira por não ter o poder efetivo de decisão de fato.

Aranda (2014, p. 270) corrobora que "a democracia não tem conseguido se articular a uma concepção que legitime seus próprios valores, e, empiricamente é afirmado por muitas bocas que a participação é reduzida, é restrita, é mínima”.

Piana (2009, p. 67), salienta que tal fato se explica: "visto que a educação sempre esteve a serviço de um modelo econômico de natureza concentradora de rendas e socialmente excludente". De fato, a educação como política pública sempre atendeu aos interesses do capitalismo.

Logo [...] "qualquer ação política que se respalde na organização da teoria social do capitalismo, constituir-se-á num elemento paliativo [...] Lima; Aranda; Lima; (2013, p. 56).

Estudos realizados por Aranda (2014) evidenciam que o Estado pós 1988, tentou por diversas vezes através de projetos, programas persuadir e evidenciar que as massas estavam de alguma forma "participando" das decisões e precisavam participar para melhorar a educação do país. Porém como veremos é apenas discurso de uma política educacional neoliberal que não tem fundamentos sociais e humanos.

O Plano Decenal de Educação para todos - PDEpt em 1993 tinha como objetivo o voluntarismo ou participação voluntária. Em 1995 foi criado o "acorda Brasil - Está na hora da Escola" e o programa "Toda Criança na Escola com intuito de estimular a parcerias entre o poder público e empresas. Outro exemplo de iniciativa que envolveu a área privada foi o Programa “Amigos da Escola”. São programas que não tem concepção de participação voltada para a promoção humana e qualidade social da educação mais sim atende os interesses projetados pelos ideais liberais em uma sociedade capitalista (ARANDA, 2014).

Veja que todos os programas acima citados planejado pelo Estado numa concepção inicial e ingênua da sociedade esses projetos pressupõe participação, porem este tipo de modelo de participação, adverte Lima; Aranda; Lima (2013, p. 56) “nem sempre se sustenta em um 


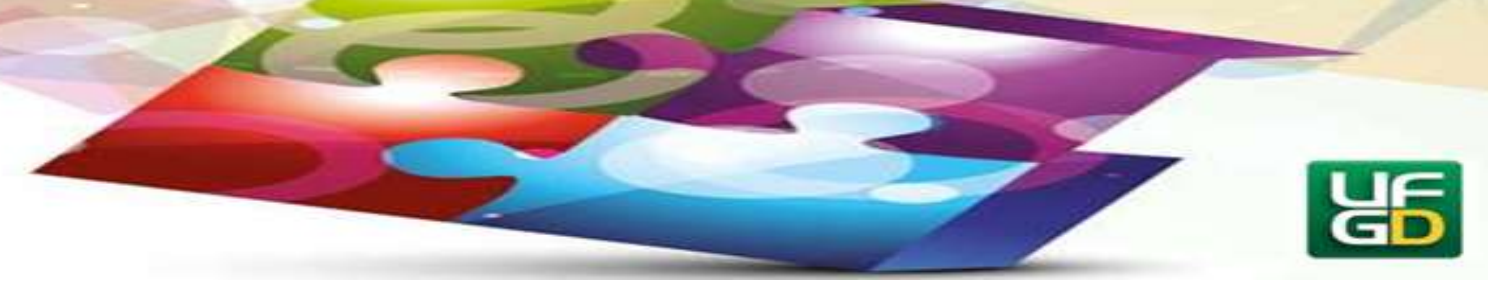

princípio que inspire um compromisso social e político que venha a assegurar uma concepção de educação que conceba o homem como sujeito da história e não sujeitado a ela".

Essa participação não faz do homem sujeitos da sua própria história, mas os alienam cada fez mais. Pois tais programas têm como objetivos a manutenção do capital. Eles evidenciam que o fator econômico tem grande e ou total influência na política educacional brasileira. Em outras palavras, o velho capitalismo perverso que se renova a cada crise em busca da perpetuação da hegemonia da classe dominante.

Matias; Raimann (2015, p. 88-89), afirmam que “os impactos de modelo de produção capitalista na educação levam a uma disputa entre dois projetos antagônicos de ideal de educação e de escola um conservador e o outro mais progressista". Modelos totalmente opostos.

O primeiro a serviço do capital que tem como ideologia fomentar a parceria público e privado e incentivar a participação restrita e cautelada que só tem um objetivo transferir a responsabilidade do estado para a sociedade. Para Lima, $(2015$, p. 93) "tal procedimento reduz a participação ao preenchimento burocrático [...]". O segundo projeto progressista é como dizia o educador Paulo Freire (1996) é libertador e autônomo. Ou seja, uma participação completa, emancipadora e crítica. Uma verdadeira cidadania ampliada. Este modelo é comprometido com a qualidade social da educação, com a formação de sujeitos como um todo.

É preciso, portanto que o ato de participação dos sujeitos não seja meramente burocrático ou para atender aos interesses do capital. É para tanto é necessário e urgente que os trabalhadores tenham consciência do seu papel na sociedade e comecem a entender o que significa democracia e participação. Lima (2015) corrobora:

Ao entender a dimensão da democracia, os protagonistas sócios não mais aceitarão orientações ou deliberações centralizadas, porque a ação da consciência coletiva não admitirá a democratização como um verniz, mas como o centro do processo validado pela legitimação conferida por todos (LIMA, 2015, p. 97).

Somente com a consciência dos trabalhadores em não aceitar projetos com origem neoliberal é que a participação será efetivada e não tutelada pelo Estado através de projetos e programas com esse foco. 


\section{Considerações Finais}

O objetivo desse estudo foi discutir a concepção de participação como princípio da gestão democrática na legislação educacional do nacional ao local. Lima P. (2015, p. 10) adverte que a "Democracia procede da democratização, esta que por sua vez, depende de participação". E "participação não é participacionismo, requer engajamento e poder compartilhado, que se pulveriza no coletivo" Raimann (2015, p. 59).

Lima A.; Aranda; Lima P. (2013, p. 57) analisam que “[...] a democracia não tem conseguido se articular a uma concepção que legitime seus valores efetivos e empiricamente é afirmado que a participação é reduzida, restrita, mínima, controlada, regulada, cooptada, [...]”.

Nesse sentido, Azevedo (2017, p. 36), explica que “apesar dos limites que a condiciona, a democracia é, sem dúvida, a melhor forma de governo que a humanidade conseguiu vivenciar/alcançar até o presente".

O princípio de gestão democrática pressupõe participação, autonomia e descentralização. Por meio da gestão democrática é possível proporcionar um ambiente coletivo com representatividade de segmentos, que aceita a participação de todos os envolvidos de modo crítico.

Por tudo isso, Dourado (2007), afirma que a gestão democrática é processo de aprendizado e de luta política. "É hoje, mais do que nunca, um valor consagrado no Brasil e no mundo, embora ainda não totalmente compreendido e incorporado à prática social global e à prática educacional brasileira e mundial” Ferreira (2001, p. 167).

E completa a autora é “indubitável sua importância como um recurso de participação humana e formação para a cidadania. É indubitável sua necessidade para a construção de uma sociedade mais justa e igualitária. É indubitável sua importância como fonte de humanização" (Ibid.).

Em resumo, gestão democrática e participação, se concebidas apenas pela legislação, pelo "cumpra-se", podem vir a ser "letra morta". Como por exemplo a Meta 19 acima citada, não "contempla na sua essência a gestão democrática do ensino, pois reduz a esta [...] à meritocracia" (BERNARDO; BORDE 2016, p. 267). Entretanto, se fundamentadas e compreendidas em uma concepção de sociedade, educação, ser humano de viés crítico e 


\section{HORIZONTES - REVISTA DE EDUCACATO}

E-ISSN: 2318-1540

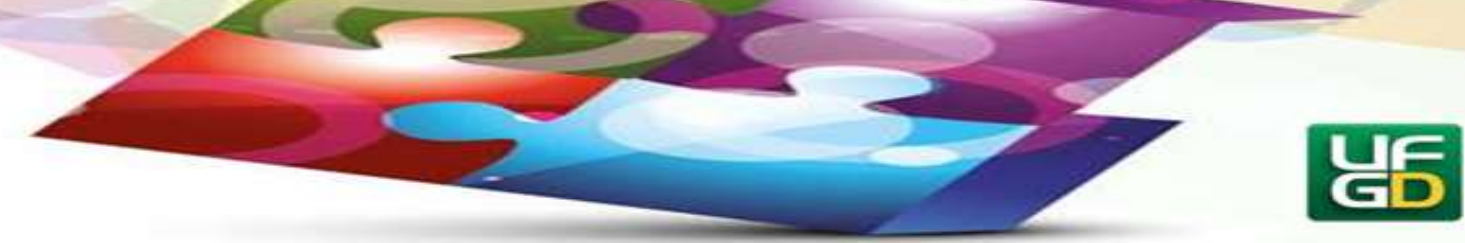

emancipador, poderão vir a ser incorporadas "à prática social global e à prática educacional brasileira e mundial" e possibilitar o caminhar para "uma sociedade mais justa e igualitária".

\section{Referências Bibliográficas}

FERREIRA, Aurélio Buarque de Holanda. Dicionário da língua portuguesa. 5. ed. : São Paulo: Papirus, 2018.

ARANDA, Maria Alice de Miranda. A 'restrita' cidadania ampliada presente nas ações da política social. Crítica Educativa, São Paulo, v. 1 n $^{\text {a }}$ 1, jan./jun., 2015. Disponível em: $\langle$ http://www.criticaeducativa.ufscar.br/index.php/criticaeducativa/article/view/23/170>. Acesso em: 17 dez. 2017.

ARANDA, Maria Alice de Miranda. A Participação como Princípio da Gestão Democrática: O Debate Pós Ditadura Militar. Revista HISTEDBR On-line, Campinas, nº 56, p. 266-279, mai. 2014 - ISSN: 1676-2584.

ARANDA, Maria Alice de Miranda; LIMA, Franciele Ribeiro. O Plano Nacional de Educação e a Busca pela Qualidade Socialmente Referenciada. Educação e Políticas em Debate, v. 3, 2014. p. 291-313.

ARANDA, Maria Alice de Miranda. O significado do princípio da participação na política educacional brasileira nos anos iniciais do século XXI: o declarado no PPA "Brasil de Todos 2004-2007. 234f. Tese (Doutorado em Educação). Universidade Federal de Mato Grosso do Sul. Campo Grande, MS, 2009.

AZEVEDO, Janete Maria Lins de. Democracia, Democratização e Conselhos. In: LIMA, Antônio Bosco de (Org.). CMEs no Brasil: Qualidade Social e Política da Educação.

Campinas, SP, Editora Alineia, 2017, p. 35-45

BERNADO, Elisangela da Silva; BORDE, Amanda Moreira. PNE 2014-2024: uma reflexão sobre a meta 19 e os desafios da gestão democrática. Revista Educação e Cultura Contemporânea, v 13, $\mathrm{n}^{\circ} 33$. 2016. Disponível em < http://periodicos.estacio.br/index.php/reeduc/article/viewFile/2423/1291 >. Acesso em: 29 jan. 2019.

BOBBIO, Norberto. O futuro da democracia: uma defesa das regras do jogo. $6^{\mathrm{a}}$ ed. Rio de Janeiro: Paz e Terra, 1997.

BRASIL. Lei 13.005, de 25 de junho de 2014. Aprova o Plano Nacional de Educação - PNE, e dá outras providências. Brasília, DF: Câmara dos Deputados, 2014. Disponível em:<http://www.observatoriodopne.org.br/uploads/reference/file/439/documentoreferencia.pdf $>$. Acesso em: jul./2017.

BRASIL. Ministério da Educação. Lei n ${ }^{\circ}$ 9394/96, de 20 de dezembro de 1996. Estabelece as Diretrizes e Bases da Educação Nacional. Brasília: MEC, 1997. 


\section{HORIZONTES - REVISTA DE EDUCACATO}

E-ISSN: 2318-1540

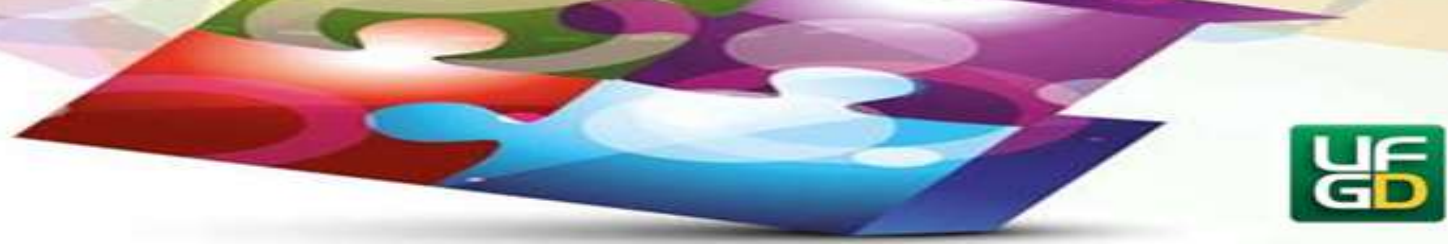

BRASIL. Constituição (1988). Constituição da República Federativa do Brasil. Brasília, DF: Senado, 1988.

CARNOY, Martin. Estado e teoria política. (Equipe de tradução: PUCCAMP). $2^{a}$ ed. Campinas: Papirus, 1988.

CURY, Carlos Roberto Jamil. Gestão democrática da Educação: Exigências e desafios. Revista RBPAE. Vol. $18 \mathrm{n}^{\circ}$ 02. Campinas. Jul./dez 2002. Disponível em:< http://seer.ufrgs.br/index.php/rbpae/article/view/25486/14810 >. Acesso em: nov. 2017.

DOURADOS. Lei n ${ }^{\circ} 3.904$, de 15 de junho de 2015. Aprova o Plano Municipal de Educação - PME e dá outras providências. Disponível em: <http://www.dourados.ms.gov.br/wpcontent/uploads/2015/11/PME-Dourados-2015-Vers\%C3\%A3o-Final-1.pdf >. Acesso em: jul./2017.

DOURADO, Luis Fernandes. Políticas e gestão da educação básica no Brasil: limites e perspectivas. Educ. Soc., Campinas, vol. 28, n. 100 - Especial, p. 921-946, out. 2007. Disponível em: 〈http://www.scielo.br/pdf/es/v28n100/a1428100〉. Acesso em: dez. 2016.

FERREIRA, Naura Syria Carapeto; AGUIAR, Márcia Ângela da S. (Orgs.). Gestão da educação: impasses, perspectivas e compromissos. São Paula: Cortez, 2001.

FREIRE, Paulo. Pedagogia da autonomia: Saberes necessários à prática educativa. São Paulo: Paz e Terra. 1996.

HUME, David. Investigação acerca do entendimento humano. Tradução AnoarAiex. São Paulo, SP: Nova Cultura Ltda., 1999. (Coleção Os pensadores).

LIMA, Paulo Gomes; ARANDA, Maria Alice de Miranda; LIMA, Antônio Bosco. Participação e políticas educacionais e o plano da efetividade, a possibilidade e a necessidade de gestão democrática. 2013. Disponível

em:<http://www.scielo.br/pdf/epec/v14n1/1983-2117-epec-14-01-00051.pdf>. Acesso em: Dez/2017.

MATO GROSSO DO SUL. Lei $N^{o} 4.621$, de 22 de dezembro de 2014. Aprova o Plano Estadual de Educação de Mato Grosso do Sul, e dá outras providências. 2014. Disponível em: $<$ http://www.sed.ms.gov.br/wp-content/uploads/sites/67/2015/05/Plano-Estadual-deEduca\%C3\%A7\%C3\%A3o-MS.pdf >. Acesso em: 09 jan. 2019.

OLIVEIRA, Romualdo Portela de; ARAÚJO, Gilda Cardoso de. Qualidade do ensino: uma nova dimensão da luta pelo direito à educação. 2005. Disponível em: <http://www.scielo.br/pdf/rbedu/n28/a02n28.pdf>. Acesso em: 14 dez. 2017.

PIANA, Maria Cristina. As políticas educacionais: dos princípios de organização à proposta da democratização. 2009. Disponível em: <http://books.scielo.org/id/vwc8g/pdf/piana9788579830389-03.pdf>. Acesso em: 17 dez. 2017. 


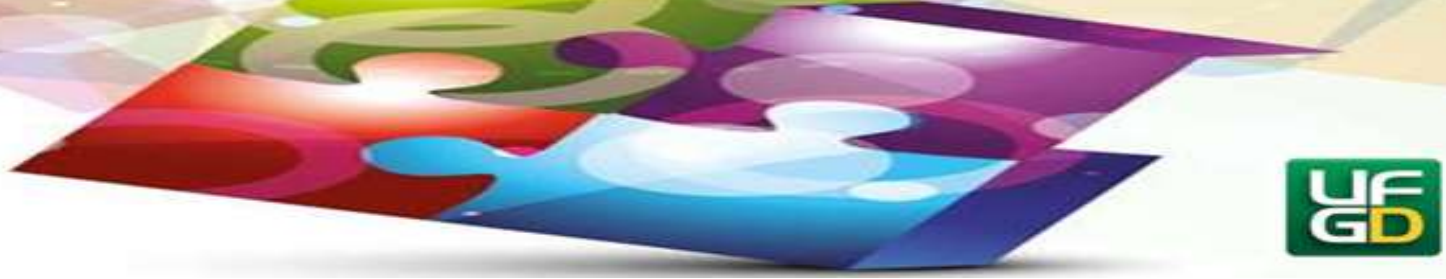

RAIMANN, Ari. PPP: a gestão e a qualidade da educação. In: LIMA, Antônio Bosco de. (Org.) PPP- Participação gestão e qualidade da educação. Uberlândia, MG. Assis Editora, 2015 , p. $49-62$.

SAVIANI, Demerval. Política Educacional Brasileira: limites e perspectivas. Revista de Educação PUC. Campinas, no 24, jun. 2007. Disponível em: $<$ http://periodicos.puccampinas.edu.br/seer/index.php/reveducacao/article/view/108/96>. Acesso em: 14 nov. 2017.

SPÓSITO, Marília Pontes. Educação, gestão democrática e participação popular. BASTOS, In: JOÃO, Baptista (Org.). Gestão democrática. 4ed. Rio de Janeiro: DP\&A, 2005, p. 45 - 56.

Enviado: 05/04/2019

Aceito: 01/07/2019 